\title{
Coronin3 Promotes Nasopharyngeal Carcinoma Migration and Invasion by Induction of Epithelial-to-Mesenchymal Transition [Retraction]
}

\author{
Fan L, Wei Y, Ding X, Li B. Onco Targets Ther. \\ 2019;12:9585-9598.
}

At the request of the authors, the Editor and Publisher of OncoTargets and Therapy wish to retract the published article.

We were notified by the authors of potential issues relating to the reliability of the data in the published article. There was also some potential image duplication in Figure 5:

- Figure 5A Migration Panel CNE-1-vector appears to be duplicated with Figure 5A Invasion CNE-1-vector.

- Figure 5A Migration Panel CNE-1-C3 appears to be duplicated with Figure 5A Invasion CNE-1-C3.
- Figure 5D CNE-2-ShCntrl Panel 24H appears to be duplicated with Figure 5D CNE-2-ShC3 Panel 24H.

The authors were unable to provide the required raw data for this study and the editor determined the findings of the study were no longer supported and agreed with the authors request for the article to be retracted. The authors wish to apologise for this error.

Our decision-making was informed by our policy on publishing ethics and integrity and the COPE guidelines on retraction.

The retracted article will remain online to maintain the scholarly record, but it will be digitally watermarked on each page as "Retracted".

\section{Publish your work in this journal}

OncoTargets and Therapy is an international, peer-reviewed, open access journal focusing on the pathological basis of all cancers, potential targets for therapy and treatment protocols employed to improve the management of cancer patients. The journal also focuses on the impact of management programs and new therapeutic agents and protocols on patient perspectives such as quality of life, adherence and satisfaction. The manuscript management system is completely online and includes a very quick and fair peer-review system, which is all easy to use. Visit http://www.dovepress.com/ testimonials.php to read real quotes from published authors. 